Artigo

\title{
Avaliação dos Órgãos de Controle Interno nos Poderes Municipais Brasileiros: análise a partir dos regulamentos legais
}

\author{
Control in Internal Organs of Assessment Powers Municipal Brazilian: \\ analysis from the legal regulations
}

Evaluación de los Organismos de Control Interno en Competencias Municipales en Brasil: análisis de las normas legales

Gleice Carvalho de Lima Moreno ${ }^{1}$, Luiz Carlos Miranda ${ }^{2}$

1 Filiação institucional. Mestre Pelo Programa de Pós-Graduação em Ciências Contábeis da Universidade Federal de Pernambuco, Brasil, e docente da Faculdade Panamericana de Ji-Paraná, Ji-Paraná, RO, Brasil.

Correspondência: $\quad$ E-mail: gleice.cl11@gmail.com

${ }^{2}$ Filiação. Mestre Pelo Programa de Pós-Graduação em Controladoria e Contabilidade da Universidade de São Paulo, Brasil, doutorado pelo Programa de Pós Graduação em Agribusiness da University of Illinois, Estados Unidos. Atualmente é Professor Titular no Departamento De Ciências Contábeis e Atuariais e docente no Programa de Pós-Graduação em Ciências Contábeis da Universidade Federal de Pernambuco, Recife, PE, Brasil.

Correspondência: $\quad$ E-mail: mirandaphd@gmail.com

Resumo $\quad$ O combate à fraude e à corrupção tem sido uma ação incessante no setor público. Para isso, o Sistema de Controle Interno (SCI) foi criado há pouco tempo nos municípios brasileiros, com o propósito de exercer a fiscalização dos atos realizados pela administração pública. Têm-se, por exemplo, os casos das cidades do Rio de Janeiro e de São Paulo, cujo Tribunal de Contas do Município, órgão responsável por auxiliar o controle externo, ainda não havia proposto regulamentos legais para implantação do SCl. Neste caso, ficando a critério dos Poderes Municipais. Em São Paulo a unidade criada não estava subordinada ao Chefe do Poder, desvinculando-a da independência que precisa para executar suas atividades. No Rio de Janeiro foi definido cargos de provimento em comissão para a unidade de controle interno, que não garante total independência no desenvolver do exercício. Corroborando 
com esse comentário, Neu, Everett e Rahaman realizaram um estudo que contribuiu para a compreensão de como e por que a fraude e a corrupção podem ocorrer no setor público. Eles examinaram o Governo Canadense e concluíram que a independência, garantida aos servidores, é essencial para o desenvolvimento das atividades. Diante disso, esta pesquisa busca avaliar a adequação dos regulamentos legais, que instituem o SCI nos Poderes Municipais, às normas técnicas e às melhores práticas, recomendadas pela literatura. Para isso, foram analisadas as estruturas dos atos institucionais criados pelos Tribunais de Contas e sua aplicação nos Poderes Municipais. Nos resultados obtidos, pôde-se concluir que os regulamentos legais criados pelos Poderes Municipais com orientação dos Tribunais de Contas não estão atendendo às melhores práticas evidenciadas pela legislação vigente, normas técnicas e bases teóricas. Desta maneira, recomenda-se a expansão de estudos que possam dar continuidade a este, explorando outros municípios, para avaliar o comportamento da unidade de controle interno em outras regiões.

Palavras-chaves: Controle Interno; Sistema de Controle Interno; Auditoria; Poderes Municipais; Tribunais de Contas.

Abstract

The fight against fraud and corruption has been a constant action in the public sector. For this, the Internal Control System (ICS) was created recently in Brazilian municipalities, in order to carry out the review of the acts carried out by the government. We have, for example, the cases of the cities of Rio de Janeiro and São Paulo, which the Court of the City, body responsible for assisting the external control, had not yet proposed legal regulations for $\mathrm{SCl}$ deployment. In this case at the discretion of the Municipal Powers. In São Paulo the unit created was not subject to the Head of Power, deviating from the independence to perform its activities. In Rio de Janeiro was set appointment to offices in commission for the unity of internal control, it does not guarantee full independence to develop the exercise. Corroborating this review, Neu, Everett and Rahaman conducted a study that contributed to the understanding of how and why that fraud and corruption may occur in the public sector. They examined the Canadian Government and concluded that Independence, guaranteed to servers, it is essential for the development of activities. Therefore, this research aims to assess the adequacy of legal regulations, establishing the $\mathrm{SCl}$ in the Municipal Powers, technical standards and best practices recommended in the literature. For this, we analyzed the structures of institutional acts created by the Courts of Auditors and its application in the Municipal Powers. The results obtained, we can conclude that the legal regulations created by the Municipal Powers with guidance from audit offices are not meeting best practices highlighted in the current legislation, technical standards and theoretical bases. Thus, we recommend the expansion of studies to continue this by exploring other municipalities to assess the behavior of the internal control unit in other regions. Por lo tanto, esta investigación tiene como objetivo evaluar la adecuación de la normativa legal, el establecimiento de la $\mathrm{SCl}$ en el Poder Municipal, las normas técnicas y las mejores prácticas 
recomendadas en la literatura.

Keywords: Internal Control; Internal Control System; Audit; Municipal powers; Audit Courts.

Resumen La lucha contra el fraude y la corrupción ha sido una acción constante en el sector público. Para ello, el Sistema de Control Interno (SCI) fue creado recientemente en los municipios brasileños, con el fin de llevar a cabo la revisión de los actos llevados a cabo por el gobierno. Tenemos, por ejemplo, los casos de las ciudades de Río de Janeiro y São Paulo, cuyo Condado de la Corte, el órgano encargado de asistir al control externo, aún no habíamos propuesto normas legales para el despliegue de SCl. En este caso, a discreción de las competencias municipales. En São Paulo la unidad creada no estaba sujeta a la cabeza del Poder, desviándose de la independencia para ejecutar sus actividades. En Río de Janeiro se fijó la cita a las oficinas de la comisión por la unidad de control interno, que no garantiza la plena independencia para desarrollar el año. Corroborando esta revisión, Neu, Everett y Rahaman realizaron un estudio que contribuyó a la comprensión de cómo y por qué puede ocurrir que el fraude y la corrupción en el sector público. Examinaron el Gobierno canadiense y llegaron a la conclusión de que la independencia garantizada a los servidores, es esencial para el desarrollo de las actividades. Para ello, se analizaron las estructuras de los actos institucionales creados por los Tribunales de Cuentas y su aplicación en las competencias municipales. Los resultados, podemos concluir que las normas jurídicas creadas por los Poderes Municipales con la orientación de las oficinas de auditoría no están cumpliendo con las mejores prácticas de relieve en la legislación vigente, las normas técnicas y las bases teóricas. De este modo, se recomienda la ampliación de estudios para continuar esta explorando otros municipios para evaluar el comportamiento de la unidad de control interno en otras regiones.

Palabras Clave: Control Interno; Sistema de Control Interno; Auditoría; Poderes municipales; Tribunales de Cuentas. 


\section{Introdução}

A falta de controle interno no ambiente público, tem favorecido aos casos de fraude e corrupção. Isso ocorre, pela implantação ainda embrionária das unidades de controle interno nos Poderes Municipais, especificamente, no Executivo e no Legislativo, apesar de a Lei 4.320/64 e a Constituição Federal de 1988 já se referirem ao Sistema de Controle interno $(\mathrm{SCl})$. Alguns casos que podem ser considerados como exemplo, são os casos das cidades do Rio de Janeiro e de São Paulo, que apresentam algumas fragilidades no tocante ao controle interno. Isso porque, a unidade de controle interno criada pelo Poder Executivo do Município de São Paulo não estava subordinada ao Chefe do Poder, desvinculando-a da independência que precisa para executar suas atividades. No Rio de Janeiro quando houve a criação da unidade de controle interno, foi definido cargos de provimento em comissão para essa unidade, não garantindo total independência no desenvolver do exercício. Dessa forma, a ineficiência do controle interno e da auditoria interna nos Poderes Municipais, tem contribuído para a ocorrência de corrupção e fraude sem limites. Corroborando com o comentário anterior Neu, Everett e Rahaman (2010) desenvolveram uma pesquisa, tomando por base o Programa de Governo Canadense, com o propósito de avaliar o porquê da ocorrência de fraudes e corrupção envolvendo o setor público e constataram que a independência do auditor, por si só não garante, que ações ilegais sejam descobertas a tempo.

Diante disso, a proposta desta pesquisa firma-se em avaliar a adequação dos regulamentos legais, que instituem os Sistemas de Controle Interno nos Poderes Municipais, em relação à legislação vigente, às normas técnicas e às melhores práticas, recomendadas pela literatura. O estudo investiga, se os regulamentos legais editados para a implantação e manutenção dos Sistemas de Controle Interno, estão sendo criados de forma adequada ao que prevê a Legislação Brasileira, as Normas Técnicas e as bases teóricas.

Ao evidenciar a temática abordada, outros pesquisadores como Silva (2009a) investigou o grau de estruturação dos sistemas de controle interno das Prefeituras Municipais Pernambucanas, considerando o modelo conceitual do Committee of Sponsoring Organization of the Treadway Comission (COSO) adotado pela International Organization of Supreme Audit Institutions (INTOSAI), organizações não governamentais, autônomas e independentes, que propõem padrões de controle interno para entidades privadas e públicas. A coleta de dados, realizada nessa pesquisa, foi obtida através de um instrumento de verificação (check list), aplicado em uma amostra de 37 (trinta e sete) Prefeituras do Estado de Pernambuco. Os resultados identificaram diversas fragilidades, concluindo que é baixo o grau de estruturação dos sistemas de controle interno. Silva (2009b) examinou o controle interno na gestão pública municipal do Estado da Bahia para os Municípios de pequeno porte. A coleta de dados ocorreu a partir de análise documental. A pesquisa constatou que, o sistema de controle interno apesar de ser de ordem legal, na maioria das Administrações Municipais do 
Estado da Bahia ainda não se institucionalizou ou o implantou de forma precária, contrariando uma das principais funções da administração pública, que é de controlar, afetando negativamente a função de planejamento, uma vez que essas funções são interligadas. Moreno et al. (2014) avaliou se as normas editadas pelos Tribunais de Contas Municipais e Estaduais (TCs) brasileiros, orientavam os Poderes Executivos e Legislativos Municipais na implantação dos Sistemas de Controles Internos (SCls). A amostra considerou instruções e legislações de 16 Tribunais de Contas, identificando que os atos institucionais deixaram de incluir informações que poderiam contribuir para a melhor institucionalização dos Sistemas de Controles Internos nos municipios.

Diante desta discussão, observa-se que os Poderes Municipais detêm recursos públicos para a manutenção, funcionamento de suas atividades e prestação de serviços à sociedade, necessitando da aplicação do controle para garantir o correto uso desses recursos. Com isso, busca-se responder nesta pesquisa ao seguinte problema: Será que os regulamentos legais que instituem o sistema de controle interno nos poderes municipais estão atendendo à legislação e às melhores práticas, recomendadas pela literatura?

Para responder a essa questão, realizou-se o levantamento dos regulamentos legais por município no período de 2012, sua posterior análise em confronto com as determinações legais em vigor e com os aspectos teóricos, tendo como objetivo principal avaliar se os regulamentos legais, que instituem os Sistemas de Controle Interno nos Poderes Municipais, estão atendendo à legislação em vigor e às melhores práticas, recomendadas pela literatura.

\section{Sistema de Controle Interno}

Foi empreendida uma pesquisa de campo com o objetivo de relativizar situações enfrentadas pelas cooperativas de catadores de materiais recicláveis, mas, sobretudo, a de identificar as perspectivas e limites das políticas públicas voltadas à coleta seletiva, além das positividades e negatividades das cooperativas e oportunidades e ameaças enfrentadas pelas mesmas.

O sistema de controle interno nas entidades públicas teve início a partir da Lei 4.320/64, que evidenciou o controle interno e externo para serem realizados pelos Poderes Executivos e Legislativos respectivamente e o Decreto Lei 200/67 que dispõe sobre a organização da Administração Federal, estabelecendo diretrizes para a reforma administrativa. A Constituição Federal de 1988 em seus Arts. 70 e 74 faz menção ao Sistema de Controle Interno, tratando da fiscalização e da finalidade aplicados aos três Poderes.

A Lei 8.666/93 estabelece regras sobre licitações e contratos administrativos pertinentes a obras, serviços, inclusive de publicidade, compras, 
alienações e locações no âmbito da Administração Pública em suas três esferas. Fazendo referência ao sistema de controle interno em seu Art. 113.

Os Poderes deverão manter seus próprios Sistemas de Controle Interno para controlar os atos da administração pública, o cumprimento dos limites financeiros e o alcance aos objetivos propostos, conforme consta no Art. 75 da Lei 4.320/64. Um sistema único de controle interno empregado pelo Poder Executivo gera o controle interno apenas para o Órgão onde foi constituído.

A integração desses sistemas é fundamental para a geração de informações pelo Governo Municipal, atendendo às determinações da LRF por meio de sistema uniformizado de forma a garantir a prestação de contas em tempo hábil e a transparência dos resultados, como trata o Art. 56 da Lei de Responsabilidade Fiscal (Silva, 2012).

É dever do sistema de controle interno, além de garantir que os controles estejam em pleno funcionamento, prevenir e corrigir continuamente os erros ou os desvios ocorridos em relação aos parâmetros determinados, que forem detectados durante ou depois da execução das ações realizadas no âmbito de cada entidade da administração pública, para com isso atingir a eficácia e eficiência nos seus resultados (Peter e Machado, 2007).

Jund (2008) diz que, o Sistema de Controle Interno busca por meio dos controles internos se certificar de que as ações foram executadas com legitimidade, em conformidade com a legislação pertinente e com o interesse coletivo, tendo como competência, com o auxílio da auditoria interna, a avaliação, orientação e correção nos controles que um setor exerce sobre o outro.

Quanto à institucionalização dos sistemas de controle interno, Cruz e Glock (2008) dizem que as definições do Sistema de Controle Interno devem constar em lei, sendo inadmissível a formatação através de decreto, portaria ou outro meio, cujo conteúdo expresse a visão do Prefeito, isso porque ele também deve se subordinar ao sistema.

A Instrução Normativa 01/2001 da Secretaria Federal de Controle interno (SFC), define diretrizes, princípios, conceitos e aprova normas técnicas para a atuação do Sistema de Controle Interno do Poder Executivo Federal. É tomada como modelo pelos Poderes Executivos e Legislativos Municipais, bem como, pelos Tribunais de Contas, que adaptam as instruções para as demais esferas, por ser considerado o mais bem regulamentado. 


\section{Controle Interno}

A palavra controle é de origem francesa role, designando o rol de contribuintes pelo qual se verificava a operação do arrecadador e realizando a devida fiscalização, conferência e apuração dos valores arrecadados no que diz respeito ao ambiente público, assim como, nas empresas privadas para manter a ordem dos processos (Nascimento, 2005).

Cavalheiro e Flores (2007) adicionaram à fase de planejamento a importância da efetividade de pessoal nos cargos públicos. Eles argumentaram que o planejamento e a organização dos processos e procedimentos das operações, somente teriam êxito se fossem firmados em uma estrutura de servidores de provimento efetivo, contratado por meio de concurso público. Dessa forma, evitaria a rotatividade de pessoal pela exoneração que torna ineficiente a continuidade das operações.

O Conselho Federal de Contabilidade no exercício de suas atribuições e considerando a internacionalização das normas, aprovou em 21 novembro de 2008 a NBC T 16.8, que trata do Controle Interno sob o enfoque contábil aplicado ao setor público, determinando algumas finalidades.

As atividades inerentes ao controle interno são operadas por pessoas e, por isso mesmo, não fornecem segurança absoluta. As pessoas podem cometer erros, invalidar etapas, descumprir regras, entre outros fatores, que ocasionam falhas nos processos. Para tanto, é preciso acompanhar, treinar e capacitar o pessoal para possibilitar a interação entre as equipes e a obediência às leis, aos regulamentos (compliance) e as operações, acompanhados por meio do sistema de controle interno (Oliveira, 2010).

Conforme pesquisa desenvolvida por Magalhães e Guimarães (2005), que expuseram e discutiram os resultados obtidos na análise de entrevistas realizadas com os responsáveis pelos Setores de Controle Interno em Prefeituras de cinco municípios do Estado de Minas Gerais, o fator determinante de sucesso do controle interno em uma administração pública municipal, não é o controle formal propriamente dito, é o perfil dos recursos humanos, tecnicamente qualificado e capacitado, que compõe o núcleo desse sistema. Chegaram a essa conclusão após avaliar as falhas decorrentes do perfil das equipes responsáveis pelos setores de controle interno, como: falta de conhecimento de legislação, principalmente no que se refere à licitação, contrato e convênio; total envolvimento com o gestor público, muitos deles em cargos de confiança; postura autoritária, dificultando o relacionamento com os servidores, criando assim uma barreira contra o próprio Sistema de Controle Interno; ausência de treinamento e acúmulo de funções e outros. Encerraram a pesquisa sugerindo que os cargos que demandam atividades de controle interno sejam instituídos por lei, para provimento mediante concurso público, tendo nível de escolaridade superior, garantindo, assim, o cumprimento aos objetivos propostos, por dominar 
conhecimento técnico, a legislação pertinente e os princípios básicos da administração pública.

Diante dessas proposições, nota-se que os controles internos são fundamentais para o atendimento à legislação e normas vigentes e para atingir aos objetivos traçados.

\section{Abordagem Metodológica}

Esta pesquisa teve caráter exploratório, porque há pouco conhecimento difundido no tocante às análises dos regulamentos legais instituídos pelos Poderes Municipais, para a devida criação do Sistema de Controle Interno (VERGARA, 2009). A amostra foi formada por 56 municípios com população estimada em 43 milhões, representando $22 \%$ da população brasileira. A Tabela 1 compara a população da amostra com a população estimada pelo IBGE, por Região da Federação, levantamento realizado em 2011. A maior representatividade da Região Sudeste, na amostra, em relação ao total da população, deve-se ao fato de essa Região ter municípios com grandes populações, como é o caso das cidades de São Paulo, Rio de Janeiro e Belo Horizonte. Por outro lado, as Regiões Sul e Centro-Oeste estão sub-representadas na amostra pelo fato de essas regiões terem suas populações mais bem distribuídas pelos municípios que as compõem.

Tabela 1. Representatividade da População da Amostra em Relação à População Total Estimada Por Região. Brasil, 2011

\begin{tabular}{l|c|c|c}
\hline REGIÃO & $\begin{array}{c}\text { POPULAÇÃO TOTAL DOS } \\
\text { MUNICÍPIOS DA } \\
\text { AMOSTRA } \\
\text { (a) }\end{array}$ & $\begin{array}{c}\text { POPULAÇÃO } \\
\text { TOTAL } \\
\text { ESTIMADA } \\
\text { (b) }\end{array}$ & $\begin{array}{c}\text { REPRESENTATIVIDADE } \\
\text { DA AMOSTRA } \\
(\mathrm{a} / \mathrm{b} \%)\end{array}$ \\
\hline Sudeste & 22.908 .717 & 80.974 .794 & $28,29 \%$ \\
\hline Nordeste & 10.159 .453 & 53.500 .965 & $18,99 \%$ \\
\hline Norte & 2.485 .836 & 16.094 .959 & $15,44 \%$ \\
\hline Sul & 5.195 .197 & 27.561 .827 & $18,85 \%$ \\
Oentro- & 2.444 .887 & 14.243 .951 & $17,16 \%$ \\
\hline Brasil & 43.194 .090 & 192.376 .496 & $22,45 \%$ \\
\hline
\end{tabular}

IBGE (2011) 
A coleta de dados ocorreu com o uso do buscador Google. Essa ferramenta busca informações na rede mundial de computadores, por possuir pequenos códigos chamados spiders (googlebots) que são otimizados, por meio de uma varredura periódica, indexando ou armazenando os sites em seus servidores, com o propósito de possibilitar a busca da informação de forma mais eficiente possível. Dessa forma, investigou-se junto aos portais eletrônicos dos órgãos Municipais, objeto deste estudo, se foi criado regulamento legal para a implantação da unidade de controle interno, se as regras estabelecidas foram baseadas na Legislação em vigor e nas Normas Técnicas, se emitem Relatório do Sistema de Controle Interno e quais pontos são abordados nesse relatório. Analisaram-se na amostra selecionada, os regulamentos legais editados pelos Poderes Executivos e Legislativos Municipais no período de Janeiro até Maio de 2012.

Os critérios analisados nos regulamentos foram definidos partindo de bases legais, o que é permitido por lei e normas técnicas e, bases teóricas, atribuindo credibilidade ao trabalho por usar referências antes desenvolvidas, dando norte a essa nova análise.

\section{Análise dos resultados}

Os Poderes Executivos e Legislativos Municipais baseados nas instruções dos Tribunais de Contas, nas exigências da Legislação em vigor e das Normas Técnicas, apresentaram os resultados que são tratados a seguir.

A amostra analisada neste estudo, foi formada por 56 (cinquenta e seis) municípios, que representa $1 \%$ dos municípios brasileiros (informação obtida por meio do levantamento realizado pelo IBGE em 10 de Julho de 2011). A população que compõe os municípios explorados, compreende $22 \%$ do total da população estimada no Brasil. A Tabela 2 abaixo, demonstra como está disposta a amostra desta pesquisa.

Tabela 2. Estados e municípios selecionados. Brasil, 2011.

\begin{tabular}{c|c|c|c|c|c}
\hline $\begin{array}{c}\text { AMOSTRA/ } \\
\text { REGIÕES }\end{array}$ & NORTE & NORDESTE & SUL & SUDESTE & $\begin{array}{c}\text { CENTRO- } \\
\text { OESTE }\end{array}$ \\
\hline Estados & $\begin{array}{c}\text { PA e } \\
\text { TO }\end{array}$ & $\begin{array}{c}\text { BA, PE, CE, } \\
\text { RN e MA }\end{array}$ & $\begin{array}{c}\text { PR, RS } \\
\text { e SC }\end{array}$ & $\begin{array}{c}\text { SP, RJ, } \\
\text { MG e ES }\end{array}$ & MT e GO \\
\hline Municípios & 6 & 15 & 17 & 13 & 5 \\
\hline$\%$ & $11 \%$ & $27 \%$ & $30 \%$ & $23 \%$ & $9 \%$ \\
\hline \multicolumn{2}{r}{ Fonte: Elaboração própria. }
\end{tabular}

Quanto ao porte, os municípios brasileiros são classificados nas categorias definidas pelo IBGE (2007). Com essas categorias, realizou-se o levantamento da população estimada pelo IBGE no ultimo recenseamento, correlacionando esses dados à classificação pelo porte. Constatou-se que foram 
contemplados todos os portes tendo maior concentração nos municípios classificados como sendo de grande porte, distribuídos na amostra selecionada (ver tabela 3).

Tabela 3. Classificação dos municípios da amostra segundo o porte populacional. Brasil, 2011.

\begin{tabular}{l|c|c|r}
\hline \multirow{2}{*}{ CATEGORIAS } & BRASIL & AMOSTRA & \multirow{2}{*}{$\%$} \\
\cline { 2 - 3 } & $\mathbf{N}$ & $\mathrm{N}$ & \\
\hline Pequeno Porte I & 3.902 & 5 & $9 \%$ \\
\hline Pequeno Porte II & 1.057 & 6 & $11 \%$ \\
\hline Médio Porte & 320 & 10 & $18 \%$ \\
\hline Grande Porte & 269 & 23 & $41 \%$ \\
\hline Metrópole & 17 & 12 & $21 \%$ \\
\hline $\begin{array}{c}\text { Total } \\
\text { Fonte: IBGE (2011) }\end{array}$ & 5.565 & 56 & $100 \%$
\end{tabular}

Apesar de a amostra dispor de 56 (cinquenta e seis) municípios, foram analisados 65 (sessenta e cinco) poderes, centralizando a atenção para os Poderes identificados como Executivo e Legislativo (ver Tabela 4).

Tabela 4. Poderes Municipais explorados na amostra. Brasil, 2011.

\begin{tabular}{l|r|r}
\hline \multicolumn{1}{c|}{ PODERES } & $\begin{array}{r}\text { FREQUÊNCI } \\
\text { A }\end{array}$ & \multicolumn{2}{|c}{$\%$} \\
\hline Poder Executivo (PE) & 49 & $75 \%$ \\
\hline Poder Legislativo (PL) & 16 & $25 \%$ \\
\hline Total & 65 & $100 \%$
\end{tabular}

Fonte: Elaboração própria

Dando início aos fatos, o primeiro ponto analisado está relacionado à criação de ato institucional desenvolvido pelos poderes, regulamentando a Unidade de Sistema de Controle Interno dos Municípios e determinando as normas e diretrizes para o seu devido funcionamento. Diante disso, apurou-se para os Poderes Executivo e Legislativo o percentual de órgãos com regulamento criado e quantos unificaram a unidade central de controle em apenas um dos poderes.

A maior parte dos poderes analisados (92\%) dispõe de regulamento legal, instituindo a criação da unidade de controle interno. Desses dispositivos, 37\% prescrevem a determinação da criação de apenas uma unidade de controle fixada no Poder Executivo. Esse procedimento é gerado, com base no Art. 31 da Constituição Federal de 1988, que considera a implantação do Sistema de Controle Interno como responsabilidade única do Poder Executivo, inibindo dessa forma a criação do Sistema de Controle Interno nos demais poderes. Esse procedimento, entra em confronto com o que está determinado nos Arts. 70 e 74 
da mesma CF e Art. 59 da LC 101/2000, que apontam a existência, de forma integrada, do Sistema de Controle Interno em cada poder abrangendo as três esferas e promovendo a fiscalização da gestão fiscal.

Tabela 5. Criação do SCI. Brasil, 2012.

\begin{tabular}{c|c|c|c|c|c|c}
\hline RESPOSTAS & PE & $\%$ & PL & $\%$ & TOTAL & $\%$ \\
\hline SIM & 47 & $96 \%$ & 13 & $81 \%$ & 60 & $92 \%$ \\
\hline NÃO & 2 & $4 \%$ & 3 & $19 \%$ & 5 & $8 \%$ \\
\hline Total & 49 & $100 \%$ & 16 & $100 \%$ & 65 & $100 \%$
\end{tabular}

Tabela 6. Exige a unificação do SCI.

Brasil, 2012.

\begin{tabular}{c|c|c|}
\hline RESPOSTAS & PE & $\%$ \\
\hline SIM & 24 & $37 \%$ \\
\hline NÃO & 41 & $63 \%$ \\
\hline Total & 65 & 100,0
\end{tabular}

Dos regulamentos analisados 74\% (48 poderes) instituíram lei específica, que conforme Castro (2011), estabelece regras para a implantação e manutenção do Sistama de Controle Interno. Mesmo assim, há poderes que não contemplam diretrizes pelo fato do projeto de lei ainda está tramitando nas Comissões das Câmaras Municipais (ver Tabela 7).

Tabela 7. Tipos de regulamentos analisados.

Brasil, 2012.

\begin{tabular}{l|c|c}
\hline \multirow{2}{*}{ REGULAMENTOS } & FREQUÊNCIA & \multirow{2}{*}{$\%$} \\
\cline { 2 - 3 } & $\mathbf{N}$ & \\
\hline Lei & 48 & $74 \%$ \\
\hline Projeto de Lei & 5 & $8 \%$ \\
\hline Decreto & 4 & $6 \%$ \\
\hline Ato Normativo & 2 & $3 \%$ \\
\hline Lei Orgânica & 2 & $3 \%$ \\
\hline Resolução & 2 & $3 \%$ \\
\hline Lei/Decreto & 1 & $2 \%$ \\
\hline Portaria & 1 & $2 \%$ \\
\hline Total & 65 & $100 \%$
\end{tabular}

Com os regulamentos legalmente definidos, cria-se a unidade central de controle interno. Não há um termo específico estabelecido na legislação em vigor para designar a área em que atuará o Sistema de Controle Interno. Por isso, os pesquisadores reuniram os termos citados nos regulamentos, base de dados para 
esse estudo, com o propósito de deduzir a nomenclatura mais utilizada (ver Tabela 8).

Diante do levantamento realizado, ficou perceptível que o termo Controladoria Geral do Município foi o mais utilizado para indicar a unidade de controle interno, essa indicação ocorreu independente do porte do município, sendo $39 \%$ para as metrópoles e $36 \%$ para os demais portes. Segundo Oliveira (2010) a área de Controladoria no setor público atua no sentido de aprimorar os controles internos, realizar estudos de interesse para decisões de investimento e planejamento, assessorando a alta administração, além de assumir o papel de fiscalizador da gestão pública. Contrários a essa visão Cruz e Glock (2008) dizem que esse é um termo inadequado, pois se restringe a um conjunto de atividades de controle que, embora centralizadas, normalmente são exercidas em nível operacional na Área de Contabilidade e Finanças.

Tabela 8. Denominação da Unidade do SCI. Brasil, 2012.

\begin{tabular}{|c|c|c|c|c|c|c|}
\hline \multirow{3}{*}{ UNIDADES } & \multicolumn{4}{|c|}{ PORTES } & \multirow{2}{*}{\multicolumn{2}{|c|}{ TOTAL }} \\
\hline & \multicolumn{2}{|c|}{ METRÓPOLE } & \multicolumn{2}{|c|}{ DEMAIS } & & \\
\hline & $\mathbf{N}$ & $\%$ & $\mathbf{N}$ & $\%$ & $\mathbf{N}$ & $\%$ \\
\hline $\begin{array}{l}\text { Controladoria } \quad \text { Geral } \\
\text { Município }\end{array}$ & 7 & $39 \%$ & 17 & $36 \%$ & 24 & $37 \%$ \\
\hline Sistema de Controle Interno & 3 & $17 \%$ & 5 & $11 \%$ & 8 & $12,5 \%$ \\
\hline Unidade de Controle Interno & 0 & $0 \%$ & 6 & $13 \%$ & 6 & $9 \%$ \\
\hline Controladoria Municipal & 0 & $0 \%$ & 5 & $11 \%$ & 5 & $8 \%$ \\
\hline $\begin{array}{l}\text { Departamento de Controle } \\
\text { Interno }\end{array}$ & 0 & $0 \%$ & 4 & $9 \%$ & 4 & $6 \%$ \\
\hline Coordenadoria do SCl & 1 & $5,5 \%$ & 3 & $6 \%$ & 4 & $6 \%$ \\
\hline $\begin{array}{l}\text { Controladoria de Controle } \\
\text { Interno }\end{array}$ & 2 & $11 \%$ & 2 & $4 \%$ & 4 & $6 \%$ \\
\hline $\begin{array}{l}\text { Unidade Central de Controle } \\
\text { Interno }\end{array}$ & 0 & $0 \%$ & 3 & $6 \%$ & 3 & $5 \%$ \\
\hline Auditoria Geral do Município & 2 & $11 \%$ & 0 & $0 \%$ & 2 & $3 \%$ \\
\hline $\begin{array}{l}\text { Sec. Municipal de Transp. e } \\
\text { Controle }\end{array}$ & 0 & $0 \%$ & 1 & $2 \%$ & 1 & $1,5 \%$ \\
\hline $\begin{array}{l}\text { Sistema de Controle Interno } \\
\text { Integrado }\end{array}$ & 1 & $5,5 \%$ & 0 & $0 \%$ & 1 & $1,5 \%$ \\
\hline Órgão Central do SCI & 0 & $0 \%$ & 1 & $2 \%$ & 1 & $1,5 \%$ \\
\hline $\begin{array}{l}\text { Núcleo Central de Controle } \\
\text { Interno }\end{array}$ & 1 & $5,5 \%$ & 0 & $0 \%$ & 1 & $1,5 \%$ \\
\hline $\begin{array}{l}\text { Secretaria Municipal de Gestão } \\
\text { e Controle }\end{array}$ & 1 & $5,5 \%$ & 0 & $0 \%$ & 1 & $1,5 \%$ \\
\hline Total & 18 & $100 \%$ & 47 & $100 \%$ & 65 & $100 \%$ \\
\hline
\end{tabular}

Fonte: Elaboração própria 
O Sistema de Controle Interno é uma unidade que presta assessoria a alta administração. Dessa forma, deve estar subordinado, de acordo com a IN 01/2001 da SFC, ao dirigente máximo da entidade, que para o caso estudado são o Chefe do Poder Executivo e o Presidente da Câmara.

Pôde-se constatar pela Tabela 9 , que $68 \%$ dos regulamentos analisados destacam a subordinação da unidade, ligada diretamente ao Chefe do Executivo ou ao Presidente da Câmara, considerados primeiro escalão, havendo uma correlação entre os municípios caracterizados como metrópole e os menores municípios, $12 \%$ indicaram subordinação aos setores abaixo do primeiro escalão e $20 \%$ se omitiram, sendo contrários ao que determina as Normas Internacionais para a Prática Profissional de Auditoria Interna, que delimita acesso direto e irrestrito a alta administração. Além disso, essas normas provenientes do IIA deixam claras as garantias para a melhor atuação dos servidores enquadrados no Sistema de Controle Interno, como sendo de independência e de acesso ilimitado aos documentos e banco de dados, propiciando a execução de suas responsabilidades.

Tabela 9. Grau de subordinação. Brasil, 2012.

\begin{tabular}{|c|c|c|c|c|c|c|}
\hline \multirow{3}{*}{ SUBORDINAÇÃO } & \multicolumn{4}{|c|}{ PORTES } & \multirow{2}{*}{\multicolumn{2}{|c|}{ TOTAL }} \\
\hline & \multicolumn{2}{|c|}{ METRÓPOLE } & \multicolumn{2}{|c|}{ DEMAIS } & & \\
\hline & $\mathbf{N}$ & $\%$ & $\mathbf{N}$ & $\%$ & $\mathbf{N}$ & $\%$ \\
\hline Primeiro escalão & 12 & $67 \%$ & 32 & $68 \%$ & 44 & $68 \%$ \\
\hline Segundo escalão & 5 & $28 \%$ & 3 & $6 \%$ & 8 & $12 \%$ \\
\hline Sem informação & 1 & $5 \%$ & 12 & $26 \%$ & 13 & $20 \%$ \\
\hline $\begin{array}{l}\text { Total } \\
\text { nte: Elaboração própria }\end{array}$ & 18 & $100 \%$ & 47 & $100 \%$ & 65 & $100 \%$ \\
\hline
\end{tabular}

No que diz respeito a descrição das garantias, conforme determinação das Normas Internacionais de Auditoria Interna, nessa apreciação, os regulamentos oriundos dos municípios classificados como pequeno, médio e grande porte apresentaram maiores percentuais: $62 \%$ determinaram independência nas atividades e $70 \%$ garantiram o acesso irrestrito aos documentos e informações pertinentes aos atos e fatos da administração pública. No que se refere às metrópoles $56 \%$ garantiu a independência e $50 \%$ o acesso ilimitado aos documentos (ver Tabelas 10 e 11).

Tabela 10. Garantias: Independência para conduzir as responsabilidades. Brasil, 2012.

\begin{tabular}{|c|c|c|c|c|c|c|}
\hline \multirow{3}{*}{ INDEPENDÊNCIA } & \multicolumn{4}{|c|}{ PORTES } & \multirow{2}{*}{\multicolumn{2}{|c|}{ TOTAL }} \\
\hline & \multicolumn{2}{|c|}{ METRÓPOLE } & \multicolumn{2}{|c|}{ DEMAIS } & & \\
\hline & $\mathbf{N}$ & $\%$ & $\mathbf{N}$ & $\%$ & $\mathbf{N}$ & $\%$ \\
\hline Oferece garantias & 10 & $56 \%$ & 29 & $62 \%$ & 39 & $60 \%$ \\
\hline Sem informação & 8 & $44 \%$ & 18 & $38 \%$ & 26 & $40 \%$ \\
\hline Total & 18 & $100 \%$ & 47 & $100 \%$ & 65 & $100 \%$ \\
\hline
\end{tabular}


Fonte: Elaboração própria

Tabela 11. Garantias: Acesso a documentos e banco de dados. Brasil, 2012.

\begin{tabular}{|c|c|c|c|c|c|c|}
\hline \multirow{3}{*}{$\begin{array}{c}\text { ACESSO } \\
\text { IRRESTRITO }\end{array}$} & \multicolumn{4}{|c|}{ PORTES } & \multirow{2}{*}{\multicolumn{2}{|c|}{ TOTAL }} \\
\hline & \multicolumn{2}{|c|}{ METRÓPOLE } & \multicolumn{2}{|c|}{ DEMAIS } & & \\
\hline & $\mathbf{N}$ & $\%$ & $\mathbf{N}$ & $\%$ & $\mathbf{N}$ & $\%$ \\
\hline Oferece garantias & 9 & $50 \%$ & 33 & $70 \%$ & 42 & $65 \%$ \\
\hline Sem informação & 9 & $50 \%$ & 14 & $30 \%$ & 23 & $35 \%$ \\
\hline Total & 18 & $100 \%$ & 47 & $100 \%$ & 65 & $100 \%$ \\
\hline
\end{tabular}

Fonte: Elaboração própria

Com a criação da unidade de controle interno, surgiram alguns postos de trabalho para execução das atividades. Como os órgãos públicos são autonômos, cabe ao chefe maior (Prefeito ou Presidente da Câmara) determinar a forma de contratação.

Tabela 12. Grau de independência - Coordenação. Brasil, 2012.

\begin{tabular}{|c|c|c|c|c|c|c|}
\hline \multirow{3}{*}{ CONTRATAÇÃO } & \multicolumn{4}{|c|}{ PORTES } & \multirow{2}{*}{\multicolumn{2}{|c|}{ TOTAL }} \\
\hline & \multicolumn{2}{|c|}{ METRÓPOLE } & \multicolumn{2}{|c|}{ DEMAIS } & & \\
\hline & $\mathbf{N}$ & $\%$ & $\mathbf{N}$ & $\%$ & $\mathbf{N}$ & $\%$ \\
\hline Efetivo & 4 & $33 \%$ & 10 & $28 \%$ & 14 & $30 \%$ \\
\hline $\begin{array}{ll}\text { Comissionado } & \\
\text { Externo } & \text { com } \\
\text { remuneração } & \end{array}$ & 6 & $50 \%$ & 19 & $53 \%$ & 25 & $52 \%$ \\
\hline $\begin{array}{l}\text { Comissionado } \\
\text { Efetivo } \\
\text { gratificação }\end{array}$ & 1 & $8,5 \%$ & 5 & $14 \%$ & 6 & $12 \%$ \\
\hline $\begin{array}{l}\text { Comissionado } \\
\text { Efetivo sem } \\
\text { gratificação }\end{array}$ & 1 & $8,5 \%$ & 2 & $5 \%$ & 3 & $6 \%$ \\
\hline Total & 12 & $100 \%$ & 36 & $100 \%$ & 48 & 100,00 \\
\hline
\end{tabular}

Fonte: Elaboração própria

Tabela 13. Grau de independência - Membros. Brasil, 2012.

\begin{tabular}{l|c|c|c|c|c|c|}
\hline \multirow{2}{*}{ CONTRATAÇÃO } & \multicolumn{2}{|c|}{ METRÓPOLE } & \multicolumn{2}{c|}{ DEMAIS } & \multicolumn{2}{c|}{ TOTAL } \\
\cline { 2 - 7 } & $\mathbf{N}$ & $\%$ & $\mathbf{N}$ & $\%$ & $\mathbf{N}$ & $\%$ \\
\hline Efetivo & 2 & $67 \%$ & 9 & $50 \%$ & 11 & $52 \%$ \\
\hline $\begin{array}{l}\text { Comissionado } \\
\begin{array}{l}\text { Externo } \\
\text { remuneração }\end{array}\end{array}$ & 0 & $0 \%$ & 3 & $17 \%$ & 3 & $14 \%$ \\
\hline $\begin{array}{l}\text { Comissionado } \\
\begin{array}{l}\text { Efetivo } \\
\text { gratificação }\end{array}\end{array}$ & 1 & $33 \%$ & 6 & $33 \%$ & 7 & $33 \%$ \\
\hline $\begin{array}{l}\text { Total } \\
\text { Fonte: Elaboração própria }\end{array}$ & 3 & $100 \%$ & 18 & $100 \%$ & 21 & $100 \%$ \\
\hline
\end{tabular}


Observa-se que, dentre as formas de contratação existentes nos regulamentos das metrópoles e demais portes, a forma que predominou foi de cargo comissionado para a coordenação, e efetivo para os demais membros. A despeito do resultado concernente ao cargo de coordenador, alguns autores (CAVALHEIRO e FLORES, 2007; MAGALHÃES e GUIMARÃES, 2005), constataram em pesquisa realizada que é imprescindível a admissão de servidores por meio de concurso público, determinando em edital o perfil que se espera do candidato aprovado, tendo em vista a complexidade das atividades a serem executadas na unidade de controle interno, bem como, para agir em conformidade com a legislação vigente (Lei Federal 10.180/2001; Constituição Federal de 1988) que estabelecem especificamente a forma de contratação para os cargos que exigem um nivelamento profissional mais apurado.

Além disso, é importante determinar as competências desses profissionais em atos institucionais, como prevê o Código de Ética do IIA (The Institute of Internal Auditors) e a Resolução CFC no 1.329/2011 que trata da NBC PI 01 (Normas Profissionais do Auditor Interno).

Tabela 14. Competências: Conhecer normas técnicas e legislação vigente. Brasil, 2012.

\begin{tabular}{|c|c|c|c|c|c|c|}
\hline \multirow{3}{*}{ SITUAÇÕES } & \multicolumn{4}{|c|}{ PORTES } & & \\
\hline & \multicolumn{2}{|c|}{ METRÓPOLE } & \multicolumn{2}{|c|}{ DEMAIS } & \multicolumn{2}{|c|}{ TOTAL } \\
\hline & $\mathbf{N}$ & $\%$ & $\mathbf{N}$ & $\%$ & $\mathbf{N}$ & $\%$ \\
\hline $\begin{array}{l}\text { Exige } \\
\text { competência }\end{array}$ & 3 & $17 \%$ & 29 & $62 \%$ & 32 & $49 \%$ \\
\hline $\begin{array}{l}\text { Sem } \\
\text { informações }\end{array}$ & 15 & $83 \%$ & 18 & $38 \%$ & 33 & $51 \%$ \\
\hline Total & 18 & $100 \%$ & 47 & $100 \%$ & 65 & $100 \%$ \\
\hline
\end{tabular}

Fonte: Elaboração própria

Tabela 15. Competências: Ter idoneidade moral. Brasil, 2012.

\begin{tabular}{|c|c|c|c|c|c|c|}
\hline \multirow{3}{*}{ SITUAÇÕES } & \multicolumn{4}{|c|}{ PORTES } & & \\
\hline & \multicolumn{2}{|c|}{ METRÓPOLE } & \multicolumn{2}{|c|}{ DEMAIS } & \multicolumn{2}{|c|}{ TOTAL } \\
\hline & $\mathbf{N}$ & $\%$ & $\mathbf{N}$ & $\%$ & $\mathbf{N}$ & $\%$ \\
\hline $\begin{array}{l}\text { Exige } \\
\text { competência }\end{array}$ & 1 & $6 \%$ & 8 & $17 \%$ & 9 & $14 \%$ \\
\hline $\begin{array}{l}\text { Sem } \\
\text { informações }\end{array}$ & 17 & $94 \%$ & 39 & $83 \%$ & 56 & $86 \%$ \\
\hline Total & 18 & $100 \%$ & 47 & $100 \%$ & 65 & $100 \%$ \\
\hline
\end{tabular}

Fonte: Elaboração própria

As atividades do Sistema de Controle Interno requerem amplo conhecimento e atualização continuada, por conta das mudanças que ocasionalmente são realizadas na legislação em vigor e normas técnicas. Para esse item, houve o tratamento nos regulamentos dos municípios considerados pequeno, médio e de grande porte, compreendendo mais de $50 \%$. No caso das metropóles 83\% (15) dos municípios não determinaram essa competência. Dessa 
forma, as categorias de porte dos municípios tratadas neste estudo, apresentaram um comportamento diferenciado. No tocante ao segundo item que trata da boa reputação, destacou-se o maior percentual para os regulamentos em que não continham tal informação, seguindo uma mesma tendência as metrópoles e os municípios de menor porte.

Em sintonia com as competências profissionais alguns autores como, Castro (2011), Cavalheiro e Flores (2007), Magalhães e Guimarães (2005), afirmam que a qualificação do profissional é extremamente importante para lidar com as atividades, que exigem um certo grau de conhecimento nas áreas de Contabilidade, Economia, Direito e Administração. Por isso, é importante a especificação nos regulamentos legais de pessoas com bom nivelamento em pelo menos uma dessas áreas. Nesse contexto, alguns regulamentos expõem o nível de formação que os servidores precisam ter para atender ao grau de complexidade das atividades.

Percebe-se que, a quantidade de itens selecionados na Tabela 16 supera o total de unidades analisadas, visto que algumas legislações especificam mais de um curso. Observa-se que há a ausência, na maior parte dos regulamentos analisados, da exigência de formação superior necessária para desenvolver as atividades. Nos documentos em que constava essa informação, os cursos que tiveram maior pontuação e com isso predominaram foram: Ciências Contábeis; Ciências Jurídicas; Ciências Econômicas; e Administração. Essa necessidade foi confirmada na opinião de Magalhães e Guimarães (2005), quando observaram que o fator determinante de sucesso do controle interno em uma administração pública municipal, não é o controle formal propriamente dito, é o perfil dos recursos humanos, tecnicamente qualificado e capacitado, para atender às atividades da unidade central de controle interno.

Tabela 16. Conhecimento exigido para ocupação dos cargos. Brasil, 2012.

\begin{tabular}{|c|c|c|c|c|c|c|}
\hline \multirow{3}{*}{ QUALIFICAÇÃO } & \multicolumn{4}{|c|}{ PORTES } & & \\
\hline & \multicolumn{2}{|c|}{ METRÓPOLE } & \multicolumn{2}{|c|}{ DEMAIS } & \multicolumn{2}{|c|}{ TOTAL } \\
\hline & $\mathbf{N}$ & $\%$ & $\mathbf{N}$ & $\%$ & $\mathbf{N}$ & $\%$ \\
\hline Ciências Contábeis & 5 & $19 \%$ & 22 & $21 \%$ & 27 & $21 \%$ \\
\hline Ciências Econômicas & 2 & $7 \%$ & 14 & $14 \%$ & 16 & $12,5 \%$ \\
\hline Administração & 3 & $11 \%$ & 19 & $18 \%$ & 22 & $17 \%$ \\
\hline Direito & 3 & $11 \%$ & 20 & $20 \%$ & 23 & $18 \%$ \\
\hline Ciências Sociais & 0 & $0 \%$ & 2 & $2 \%$ & 2 & $1,5 \%$ \\
\hline Engenharia & 1 & $4 \%$ & 2 & $2 \%$ & 3 & $2 \%$ \\
\hline $\begin{array}{l}\text { Controladoria } \\
\text { Finanças }\end{array}$ & 1 & $4 \%$ & 1 & $1 \%$ & 2 & $1,5 \%$ \\
\hline Sem especificação & 12 & $44 \%$ & 20 & $20 \%$ & 32 & $25 \%$ \\
\hline Sem Exigências & - & - & 2 & $2 \%$ & 2 & $1,5 \%$ \\
\hline
\end{tabular}




\begin{tabular}{c|c|c|c|c|} 
Total & 27 & $100 \%$ & $102|100 \%| 129 \mid 100 \%$
\end{tabular}

O conhecimento em uma das áreas já citadas assegura que as finalidades/competências/atribuições do Sistema de Controle Interno sejam realizadas de forma satisfatória, fortalecendo o resultado das atividades. Os itens selecionados para esse critério de investigação foram os mesmos utilizados na análise dos Tribunais de Contas, abrangendo a NBC T 16.8, que trata do controle interno aplicado ao setor público, as finalidades previstas na Constituição Federal de 1988 e as competências citadas na IN 01/2001 da SFC, tomada como referência pelas esferas estadual e municipal.

Mediante a apuração dos dados ficou perceptível que, as finalidades instituídas nas Normas Brasileiras de Contabilidade aplicadas ao Setor Público, que buscam a convergência com as normas internacionais de contabilidade, curiosamente foram as menos consideradas nos documentos analisados. A não consideração das finalidades dispostas na NBC T 16.8 ocorreu, porque tem sido baixa a adaptação dos procedimentos à nova sistemática que busca a harmonia entre as Normas Brasileiras de Contabilidade com as Normas Internacionais (FRAGOSO et. al., 2010). Além disso, houve a alteração do prazo para adoção das NBCASP, determinada pela Secretaria do Tesouro Nacional (STN), com uso da Portaria 828/2011. Dessa forma, a administração pública passará a cumprir as exigências, quando for determinado efetivamente por lei.

Quanto às finalidades previstas na Constituição Federal, ao contrário das tratadas nas NBCs, foram recomendadas na maior parte dos regulamentos apreciados. A aplicação dessas finalidades representou uma média de $79 \%$ (51) dos documentos analisados. Pôde-se observar que, tanto as metrópoles quanto os demais municípios seguem o mesmo procedimento: a ocorrência dessas finalidades nos regulamentos criados pelos poderes.

Para as competências constantes na IN 01/2001 da SFC, as metrópoles e as cidades de menor porte seguem uma mesma tendência, não havendo uma diferença significativa entre as frequências. Logo, 55\% dos municípios tomaram como referência a IN 01/2001 da SFC e 45\% não fazem uso dessas competências. Vale ressaltar, que essa Instrução Normativa está voltada ao Poder Executivo Federal e por se relacionar ao Sistema de Controle Interno é tomada como referência por alguns entes de outras esferas. Não sendo estas normas consideradas obrigatórias para os órgãos municipais. Contudo, a instrução foi considerada como critério de investigação, por incluir em suas competências algumas exigências da LRF e da Lei 8.666/93 que abrangem os municípios.

A seguinte recomendação que deve constar nas leis que estabelecem regras para a criação e manutenção do Sistema de Controle Interno é a elaboração e conferência dos relatórios do Sistema de Controle Interno e o de Gestão Fiscal respectivamente. 
Para o Relatório do Sistema de Controle Interno foram apreciadas as proposições de Batista (2011), que evidencia o relatório como sendo documento hábil que sintetiza o resultado das atividades realizadas pela unidade central de controle, sendo este, um indicativo de que as atividades foram devidamente acompanhadas. Esse relatório deve conter os procedimentos e medidas que serão ou já foram adotadas para corrigir e evitar as falhas ou erros percebidos durante a sondagem. Diante disso, os municípios que confirmaram a elaboração desse relatório como uma de suas regras, totalizaram $68 \%(44)$, sendo $67 \%(12)$ para os municípios classificados como metrópole e 70\% (32) para os demais portes, apresentando o mesmo comportamento no que tange a especificação desse critério no regulamento do Sistema de Controle Interno.

Tabela 17. Relatório do Sistema de Controle Interno relativo às contas. Brasil, 2012

\begin{tabular}{|c|c|c|c|c|c|c|}
\hline \multirow{3}{*}{ RESPONSABILIDADE } & \multicolumn{4}{|c|}{ PORTES } & \multirow{2}{*}{\multicolumn{2}{|c|}{ TOTAL }} \\
\hline & \multicolumn{2}{|c|}{ METRÓPOLE } & \multicolumn{2}{|c|}{ DEMAIS } & & \\
\hline & $\mathrm{N}$ & $\%$ & $\mathrm{~N}$ & $\%$ & $\mathrm{~N}$ & $\%$ \\
\hline $\mathrm{RCl}$ & 12 & $67 \%$ & 32 & $70 \%$ & 44 & $68 \%$ \\
\hline Sem informações & 6 & $33 \%$ & 15 & $30 \%$ & 21 & $32 \%$ \\
\hline Total & 18 & $100 \%$ & 47 & $100 \%$ & 65 & $100 \%$ \\
\hline
\end{tabular}

Fonte: Elaboração própria

Tabela 18. Relatório de Gestão Fiscal. Brasil, 2012.

\begin{tabular}{|c|c|c|c|c|c|c|}
\hline \multirow{3}{*}{ RESPONSABILIDADE } & \multicolumn{4}{|c|}{$\begin{array}{c}\text { PORTES } \\
\end{array}$} & \multirow{2}{*}{\multicolumn{2}{|c|}{ TOTAL }} \\
\hline & \multicolumn{2}{|c|}{ METRÓPOLE } & \multicolumn{2}{|c|}{ DEMAIS } & & \\
\hline & $\mathbf{N}$ & $\%$ & $\mathbf{N}$ & $\%$ & $\mathbf{N}$ & $\%$ \\
\hline RGF & 7 & $39 \%$ & 25 & $53 \%$ & 32 & $49 \%$ \\
\hline Sem informações & 11 & $61 \%$ & 22 & $47 \%$ & 33 & $51 \%$ \\
\hline $\begin{array}{l}\text { Total } \\
\text { Fonte: Elaboração própria }\end{array}$ & 18 & $100 \%$ & 47 & $100 \%$ & $65 \mid$ & $100 \%$ \\
\hline
\end{tabular}

Outra responsabilidade da unidade de controle interno é a de conferir o Relatório de Gestão fiscal, que mediante afirmação de Cruz e Glock (2008) não cabe a essa unidade emitir o relatório e sim analisar, aferir a fidedignidade das informações e assinar tal documento. Complementando, Batista (2011) diz que o Sistema de Controle Interno, deve responsabilizar-se pela veracidade do Relatório de Gestão Fiscal, nos termos do Art. 54, parágrafo único, da LC 101/2000. Considerando os dados coletados, apenas 39\% (7) das metrópoles contemplam essa exigência e 53\% (25) dos demais municípios destacam esse procedimento. Para esse caso, os municípios de menor porte estão mais avançados que as metrópoles. 
Diante dos dados analisados, pôde-se constatar que os Poderes Executivos e Legislativos Municipais não estão atendendo, em sua totalidade, aos preceitos determinados pela Legislação em vigor, Normas Técnicas e as melhores práticas convencionadas por pesquisas desenvolvidas na área pública.

\section{Conclusão}

A falta de controle interno no ambiente público, tem favorecido aos casos de fraude e corrupção. Isso tem ocorrido, por causa da implantação ainda embrionária das unidades de controle interno nos Poderes Municipais, especificamente, no Executivo e no Legislativo. Neste sentido, esta pesquisa teve o propósito de avaliar se os regulamentos legais editados para a criação do Sistema de Controle Interno nos Poderes Municipais estão de acordo com os aspectos legais e teóricos que dão norte para a implantação do controle interno e de um Sistema de Controle Interno mais seguro.

A amostra foi selecionada contemplando os municípios, seus respectivos portes populacionais e suas regiões. Foram apreciados neste estudo 65 órgãos, sendo 49 (quarenta e nove) do Executivo e 16 (dezesseis) do Legislativo. Os critérios investigados nesses documentos foram selecionados tomando por base a Constituição Federal, as NBCs, o IIA, a LC 101/2000, a Lei 4.320/1964, a IN $01 / 2001$ da SFC, a Lei 10.180/2001, o Decreto 3.591/2000, a Lei 8.666/93, a Lei 8.443/92 e o coso. Além disso, houve a seleção de uma extensa literatura, formada por pesquisas atuais e com considerações significativas.

Os resultados para os municípios comprovam que, os critérios de investigação mais indicados e que estão em conformidade com a legislação foram: criação do SCl por meio de Ato Institucional; subordinação da unidade central de controle interno ao mais alto escalão; as finalidades previstas na Constituição Federal; as garantias para os servidores dos municípios classificados como pequeno, médio e grande porte; a competência para o servidor em conhecer as normas técnicas e legislação vigente para os menores municípios; e o Relatório de Controle Interno relativo às contas.

Os principais focos de fragilidade detectados estão relacionados ao baixo grau de concordância com: metrópoles;

- as garantias para os servidores dos municípios identificados como

- o grau de independência no tocante à forma de contratação do Coordenador do $\mathrm{SCl}$, que para a maioria dos casos se procede com a disponibilização de cargo comissionado externo; 
- as competências que os profissionais precisam ter para assumir aos cargos: para as metrópoles, conhecer bem as normas técnicas e legislação em vigor; para todos os portes, a boa reputação foi menos considerada;

- a qualificação necessária para a realização das atividades, que têm certo grau de complexidade;

- as finalidades instituídas pela NBC T 16.8;

- as competências estabelecidas pela IN 01/2001 da SFC; e

- o relatório de gestão fiscal para as metrópoles.

Em resposta ao problema da pesquisa, pôde-se verificar que os regulamentos legais criados pelos Poderes Municipais, especificamente, o Executivo e o Legislativo não estão atendendo, em sua totalidade, as melhores práticas evidenciadas pela legislação vigente, normas técnicas e bases teóricas.

Neste sentido, sugere-se à Academia, a expansão de estudos que possam dar continuidade a este, explorando outros municípios e, confirmando ou não, a solidificação da unidade de controle interno em pesquisa presencial, uma vez que este estudo se limitou em avaliar a estrutura do sistema de controle interno por meio dos regulamentos legais disponíveis nos portais eletrônicos. Além disso, é interessante um estudo comparativo com o que vem sendo utilizado a nível internacional em confronto com os fatos levantados nos órgãos públicos do Brasil.

\section{Referências Bibliográficas}

Abreu, Maria Aparecida Azevedo. (2010). “Educação: um novo patamar institucional". Revista Novos Estudos, v. 87.

Constituição da República Federativa do Brasil: de 5 de outubro de 1988. (2011). São Paulo: Atlas. (34ạ ed.).

Decreto Federal no 3.591. (2000). Dispõe sobre o Sistema de Controle Interno do Poder Executivo Federal e dá outras providências. Brasília, DF: Presidência da República.

Ministério da Fazenda. (2001). Instrução Normativa 01, de 06 de abril de 2001. Define diretrizes, princípios, conceitos e aprova normas técnicas para a atuação do Sistema de Controle Interno do Poder Executivo Federal. Acesso em: 02 de janeiro de 2011, de: 
http://www.cgu.gov.br/AreaAuditoriaFiscalizacao/Arquivos/AuditoriasAnuaisEP restContas/IN_01_06042001.pdf

Lei Complementar no. 101, de 04 de maio de 2000. Estabelece normas de finanças públicas voltadas para a responsabilidade na gestão fiscal e dá outras providências. Brasília, DF: Presidência da República.

Lei Federal no. 4.320, de 17 de março de 1964. Estatui Normas Gerais de Direito Financeiro para elaboração e controle dos orçamentos e balanços da União, dos Estados, dos Municípios e do Distrito Federal. Brasília, DF: Presidência da República.

Lei Federal no. 8.666, de 21 de Junho de 93. Institui normas para licitações e contratos da Administração Pública e dá outras providências. Brasília, DF: Presidência da República.

Lei Federal 8.443/92. Dispõe sobre a Lei Orgânica do Tribunal de Contas da União e dá outras providências. Brasília, DF: Presidência da República.

Lei Federal 10.180, 06 de Fevereiro de 2001. Organiza e disciplina os Sistemas de Planejamento e de Orçamento Federal, de Administração Financeira Federal, de Contabilidade Federal e de Controle Interno do Poder Executivo Federal, e dá outras providências. Brasília, DF: Presidência da República.

Lei Federal 8.112, 11 de Dezembro de 1990. Dispõe do regime jurídico dos servidores públicos civis da União, das autarquias e das fundações públicas federais. Brasília, DF: Presidência da República.

Portaria no 828. (2011). Altera o prazo de implementação do Plano de Contas Aplicado ao Setor Público e dá outras providências. Acesso em: 03 de março de 2012, de: http://www.tesouro.gov.br/legislacao/download/contabilidade/PortSTN_828_20 111214.pdf

Batista, Daniel G. (2011). Manual de controle e auditoria: com ênfase na gestão de recursos públicos. São Paulo: Saraiva.

Castro, Domingos P. de. (2011). Auditoria, contabilidade e controle interno no setor público: integração das áreas do ciclo de gestão: contabilidade, orçamento e auditoria e organização dos controles internos, como suporte à governança corporativa. 4. ed. São Paulo: Atlas.

Cavalheiro, Jader B., \& Flores, Paulo C. (2007). “A organização do sistema de controle interno municipal. 4. ed. Porto Alegre, CRCRS". Acesso em: 23 de fevereiro de 2012, de: http://pgpp.com.br/Artigos_Controladoria/ORGANIZACAO.pdf 
cruz, Flavio. Da., \& Glock, José O. (2008). Controle interno nos municípios: orientação para a implantação e relacionamento com os tribunais de contas. 3. ed. São Paulo: Atlas.

Instituto Brasileiro de Geografia e Estatística - IBGE. Classificação dos municípios brasileiros pelo porte. (2007). Instituto de Pesquisa e Estratégia Econômica do Ceará - IPECE. Acesso em: 18 de abril de 2012, de: http://www.ipece.ce.gov.br/publicacoes/notas_tecnicas/NT_23.pdf.

Fragoso, Adriana. R., \& Ribeiro Filho, José. F., \& Lopes, Jorge E. de G., Pederneiras, Marcleide M. M. (2010). “Normas Brasileiras e Internacionais de Contabilidade Aplicadas ao Setor Público e o da Convergência: Uma análise comparativa IPSAS e NBCTSP". Em: Congresso USP de Controladoria e Contabilidade, 2010, São Paulo. Anais eletrônicos. São Paulo: USP. Acesso em: 20 de junho de 2011, de: http://www.congressousp.fipecafi.org/artigos102010/92.pdf

Jund, Sergio. (2008). Administração, orçamento e contabilidade pública. 3. ed. Rio de Janeiro: Elsevier.

Magalhães, Ana C. V., \& Guimarães, Elen R. (2005). Sistema de controle interno nos municípios: proposta de um perfil para os profissionais que atuam no núcleo desse sistema. Revista do Tribunal de Contas do Estado de Minas Gerais. Edição no 04. Acesso em: 03 de março de 2012, de: http://200.198.41.151:8081/tribunal_contas/2005/04/-sumario?next=2

Nascimento, Marcio G. do. (2005). “O controle da administração pública no estado de direito". Acesso em: 14 de março de 2011, de: http://www.direitonet.com.br/artigos/exibir/2023/O-controle-daadministracao-publica-no-Estado-de-Direito

NBC T 16.8. Normas Brasileiras de Contabilidade Aplicadas ao Setor Público Controle Interno. Acesso em: 10 de dezembro 2011, de: http://www.cfc.org.br/uparq/NBCT16_8.pdf

NBC PI 01. Normas Profissionais do Auditor Interno. Acesso em: 15 de dezembro de 2012, de: http://www.cfc.org.br/sisweb/sre/detalhes_sre.aspx?Codigo=1995/000781

Neu, Dean., \& Everett, Jeff., \& Rahaman, Abu Shiraz (2011.) “Auditing and corruption in the public sector: the case of the Canadian sponsorship program". Acesso em: 12 de fevereiro de 2012, de: http://elsevier.conferenceservices.net/resources/247/2182/pdf/CPAC2011_0097_paper.pdf

Oliveira, Antonio B. S. (2010). Controladoria governamental: governança e controle econômico na implementação das políticas públicas. São Paulo: Atlas. 
MAchado; Marcus V. V., \& Peter, Maria G. A. (2007). Manual de Auditoria Governamental. - 1. ed. - 2. Reimpr. - São Paulo: Atlas.

Moreno, Gleice Carvalho de Lima., Miranda, Luiz Carlos., \& Vasconcelos, Marco Tulio de Castro., \& Oliveira, Rezilda Rodrigues. (2014). “Avaliação das normas editadas pelos Tribunais de Contas Brasileiros para orientar os Poderes Municipais na institucionalização dos Sistemas de Controle Interno". Revista Contábil - RECONT. Volume 5, no 1.

Silva, Alan J. de M. (2009a). "Estruturação dos sistemas de controle interno de Prefeituras Municipais do Estado de Pernambuco: uma verificação baseada no modelo conceitual do COSO, adotado pela INTOSAI". Dissertação de Mestrado. Programa de Pós-Graduação em Ciências Contábeis, da Universidade Federal de Pernambuco.

Silva, Moacir M. da. (2012). Curso de Auditoria Governamental: de acordo com as Normas Internacionais de Auditoria Pública aprovadas pela INTOSAI. - 2. ed. São Paulo: Atlas.

Silva, Pedro G. da. (2009b). "Controle interno na gestão pública municipal: Modelo de um sistema de controle interno para municípios de pequeno porte do Estado da Bahia". Dissertação de Mestrado. Programa de Pós-Graduação em Ciências Contábeis, da Universidade Federal da Bahia. Acesso em: 25 de agosto de 2011, de: http://www.ppgcont.ufba.br/CONTROLE\%20INTERNO\%20NA\%20GEST\%C3\%8 30\%20MUNICIPAL.pdf

The Institute of Internal Auditors. (2009). "Normas internacionais para a prática profissional de Auditoria Interna". Acesso em: 20 de janeiro de 2012, de: http://www.iiabrasil.org.br/new/download/ippf/IPPF_Normas_01_09.pdf

Vergara, Sylvia C. (2009). Projetos e relatórios de pesquisa em administração. 11. Ed. - São Paulo: Atlas. 